\title{
Review: most antipsychotic drugs are associated with weight gain
}

Allison DB, Mentore JL, Heo M, et al. Antipsychotic-induced weight gain: a comprehensive research synthesis. Am J

Psychiatry 1999 Nov;156:1686-96.

\section{QUESTION: How much weight gain is associated with each antipsychotic drug available or undergoing clinical trials in the United States?}

\section{Data sources}

Studies were identified by searching Medline (1966 to November 1996), PsycINFO (1967 to October 1996), CINAHL (1982 to September 1996), HealthSTAR (1975 to October 1996), and Dissertation Abstracts International (1861 to January 1997); by reviewing the reference lists of identified studies; and by contacting experts in the field.

\section{Study selection}

Studies were selected if they had a human sample size $>1$, were not a review article, and measured weight change after initiating use of an antipsychotic drug.

\section{Data extraction}

Data were extracted on the number of patients in each treatment group, drug type and dose, and mean and standard deviation of weight change. A random effects estimate of weight change after 10 weeks of treatment at a standard dose was made.

\section{Main results}

81 studies met the selection criteria. Estimated weight change at 10 weeks using a random effects model is shown in the table. Both conventional and newer antipsychotic drugs are associated with weight gain. Among the newer agents, clozapine has the greatest potential to induce weight gain while ziprasidone has the least.

\section{Conclusion}

Most antipsychotic drugs are associated with weight gain.

Estimated weight change in patients taking study drugs

\begin{tabular}{ll} 
Drug & $\begin{array}{l}\text { Estimated mean weight change } \\
(\mathbf{k g}) \text { at } 10 \text { weeks }(95 \% \mathrm{Cl})^{*}\end{array}$ \\
\hline Placebo & $-0.7(-1.6$ to 0.1$)$ \\
\hline Molindone & $-0.4(-2.4$ to 1.7$)$ \\
\hline Ziprasidone & $0.04(-0.5$ to 0.6$)$ \\
\hline Fluphenazine & $0.4(-0.7$ to 1.5$)$ \\
\hline Haloperidol & $1.1(0.4$ to 1.8$)$ \\
\hline Nonpharmacologic control & $1.3(0.8$ to 1.8$)$ \\
\hline Polypharmacy & $1.8(0.8$ to 2.8$)$ \\
\hline Risperidone & $2.1(1.7$ to 2.5$)$ \\
\hline Chlorpromazine & $2.6(0.9$ to 4.3$)$ \\
\hline Sertindole & $2.9(1.8$ to 4.1$)$ \\
\hline Thioridazine/mesordazine & $3.2(1.4$ to 5.0$)$ \\
\hline Olanzapine & $4.2(3.8$ to 4.5$)$ \\
\hline Clozapine & $4.5(3.0$ to 5.9$)$ \\
\hline
\end{tabular}

Mean weight change for one drug is statistically different from another when Cls do not overlap.

\section{COMMENTARY}

Because of superior efficacy and less liability to extrapyramidal motor side effects, new antipsychotic medications represent a substantive therapeutic advance for many patients. None the less, these agents are not free of side effects. ${ }^{1}$ Weight gain is a very important clinical issue for patients taking antipsychotic medications and when severe, undermines both physical health and psychological well being. Data on weight gain associated with various first and second generation antipsychotic agents are generally derived from phase 2 and 3 clinical trials. This metaanalysis by Allison et al represents the most comprehensive summary of available data from these trials conducted to date. Results indicate substantive differences across agents in propensity to cause weight gain in short term trials: clozapine, olanzapine, and low potency typical agents are associated with greatest weight gain; ziprasidone, molindone, and high potency typical agents are associated with the least weight gain. Data concerning quetiapine, not available at the time this analysis was done, suggest weight gain in the intermediate range for this new agent. ${ }^{2}$

As Allison et al indicate, aggregated statistical data on side effects can guide but not determine selection of the optimal antipsychotic agent for an individual patient. Because our ability to predict both efficacy and side effects for a specific individual is limited, pharmacological treatment is often based on empirical, but systematic, trial and error. Aggregated data such as that presented here, however, should be of value in assisting patients and families to evaluate the potential risks and benefits of different antipsychotic agents.

It is important to recognise that the values reported in this meta-analysis are modelled to estimate average weight gain over 10 weeks of drug treatment. In practice, patients remain on maintenance antipsychotic treatment far longer-we can not be certain how these 10 week estimates hold up over prolonged treatment periods. Better data are needed to inform us about weight gain and other side effects associated with long term antipsychotic treatment.

Wayne S Fenton, MD National Institute of Mental Health Bethesda, Maryland

1 Hansen TE, Casey DE, Hoffman WF. Neuroleptic intolerance. Schizophr Bull 1997;23:567-82.

2 Arvanitis LA, Miller BG. Multiple fixed doses of "Seroquel" (quetiapine) in patients with acute exacerbation of schizophrenia: a comparison with haloperidol and placebo. The Seroquel Trial 13 Study Group. Biol Psychiatry 1997;42: $233-46$.

3 Small JG, Hirsch SR, Arvanitis LA, et al. Quetiapine in patients with schizophrenia. A high- and low-dose doubleblind comparison with placebo. Seroquel Study Group. Arch Gen Psychiatry 1997;54:549-57. 